\title{
Genetic evaluation for multiple binary responses
}

\author{
Ina HÖSCHELE ${ }^{*}$, J.L. FOULlEY ${ }^{* *}$, J.J. COLLEAU ${ }^{* *}$ and D. GIANOLA *** \\ * Universität Hohenheim, Institut 470, Haustiergenetik, \\ D 7000 Stuttgart 70 \\ ** I.N.R.A., Station de Génétique Quantitative et Appliquée, \\ Centre de Recherches Zootechniques, F 78350 Jouy-en-Josas \\ *** Department of Animal Sciences, University of Illinois, Urbana, \\ Illinois 61801, U.S.A.
}

\begin{abstract}
Summary
A method of genetic evaluation for multiple binary responses is presented. An underlying multivariate normal distribution is rendered discrete, in $\mathrm{m}$ dimensions, via a set of $\mathrm{m}$ fixed thresholds. There are $2^{\mathrm{m}}$ categories of response and the probability of response in a given category is modeled with an m-dimensional multivariate normal integral. The argument of this integral follows a multivariate mixed linear model. The randomness of some elements in the model is taken into account using a Bayesian argument. Assuming that the variance-covariance structure is known, the mode of the joint posterior distribution of the fixed and random effects is taken as a point estimator. The problem is non-linear and iteration is required. The resulting equations indicate that the approach falls in the class of generalized linear models, with additional generalization stemming from the accommodation of random effects. A remarkable similarity with multiple trait evaluation via mixed linear models is observed. Important numerical issues arise in the implementation of the procedure and these are discussed in detail. An application of the method to data on calving preparation, calving difficulties and calf viability is presented.
\end{abstract}

Key words: Multiple trait evaluation, all-or-none responses, Bayesian methods.

\author{
Résumé \\ Estimation de la valeur génétique \\ à partir de réponses binaires multidimensionnelles
}

Cet article présente une méthode d'évaluation génétique multidimensionnelle de caractères binaires. La distribution multinormale sous-jacente est discrétisée en $\mathrm{m}$ dimensions par le biais de $\mathrm{m}$ seuils. On considère les $2^{\mathrm{m}}$ catégories de réponse et la probabilité de réponse dans une catégorie est modélisée par une intégrale d'une densité multinormale de dimension $\mathrm{m}$.

L'argument de cette intégrale est décomposé suivant un modèle mixte multidimensionnel. Le caractère aléatoire de certains éléments du modèle est pris en compte par une approche bayésienne. Le mode de la distribution conjointe a posteriori est choisi comme estimateur de position des effets fixes et aléatoires sachant la structure de variances-covariances connue. Le système obtenu est non linéaire et résolu par itérations. La forme des équations montre que cette approche 
fait partie de la classe des modèles linéraires généralisés avec l'extension supplémentaire au traitement de facteurs aléatoires. Le système présente en outre une analogie remarquable avec celui de l'évaluation multi-caractère par modèle mixte linéraire. La résolution soulève d'importantes difficultés numériques. La méthode est illustrée par une application numérique à des données de préparation au vêlage, de difficulté de celui-ci et de viabilité des veaux.

Mots clés : Evaluation multicaractère, caractère tout-ou-rien, méthode bayésienne.

\section{Introduction}

Many categorical traits encountered in animal breeding are of economic importance, e.g., fertility, prolificacy, calving difficulty and viability. As their statistical treatment appears more complex than that of continuous variates, efforts have been made recently to develop procedures of analysis especially in the area of prediction of breeding values (SchaffFer \& Wilton, 1976; Berger \& Freeman, 1978 ; QuaAs \& VAN Vleck, 1980 ; Gianola, 1980a, b). A general approach to prediction of genetic merit from categorical data has been proposed by Gianola \& Foulley (1982, 1983a, b). This method, based primarily on the threshold concept, employs a Bayesian procedure for statistical inference which allows us to treat a large range of data structures and models. The method extends best linear unbiased prediction and the mixed model equations developed by Henderson (1973) to a type of nonlinear problcm. Further, it can also be regarded as an extension of estimation by maximum likelihood in "generalized linear models" (McCullagh \& Nelder, 1983) so that fixed and random effects can be accommodated.

Different situations of single trait (Gianola \& Foulley, 1982, 1983a, 1983b) and multiple trait evaluations (Foulley et al., 1983 ; Foulley \& Gianola, 1984) have already been considered. Single trait results have also been derived by GiLmour (1983) and Harville \& MeE (1984).

This report deals with the evaluation of multiple traits when each variate is a binary response. The approach is a generalization of the results in Foulley \& Gianola (1984).

\section{Methodology}

\section{A. Data}

The data can be arranged in an $s \times 2^{\mathrm{m}}$ contingency table, where $\mathrm{m}$ is the number of traits and $s$ is the number of elementary subpopulations, i.e. combirations of levels of factors or, in the most extreme form, individuals themselves. Let $n_{j, k}$ be the number of responses in subclass $\mathrm{j}(\mathrm{j}=1, \ldots, \mathrm{s})$ falling in the $\mathbf{k}^{\text {th }}$ category. The marginal totals by row $\left(n_{1+}, n_{2+}, \ldots, n_{j+}, \ldots, n_{s+}\right)$ will be assumed non-null and fixed by the sampling procedure. The $\mathrm{k}^{\text {th }}$ category can be designated by an $\mathrm{m}$-bit-digit, with a 0 and a 1 for the attributes coded [0] and [1] respectively in trait $i(i=1,2, \ldots, m)$. The data $Y$ can be presented as a $s \times 2^{\mathrm{m}}$ matrix 


$$
\mathbf{Y}^{\prime}=\left(\mathbf{Y}_{1}, \mathbf{Y}_{2}, \ldots, \mathbf{Y}_{\mathrm{j}}, \ldots, \mathbf{Y}_{\mathrm{s}}\right)
$$

where $\mathbf{Y}_{\mathrm{j}}$ is a $2^{\mathrm{m}} \times 1$ vector

$$
\mathbf{Y}_{j}=\sum_{q=1}^{n_{j}+} \mathbf{Y}_{j q}
$$

and $\mathbf{Y}_{\mathrm{jq}}$ is a $2^{\mathrm{m}} \times 1$ vector having a 1 in the position of the category of response and 0 elsewhere.

\section{B. Model}

The model is based on the threshold and liability concepts commonly used in quantitative genetics for the analysis of categorical responses (WRIGHT, 1934; ROBERTSON \& Lerner, 1949 ; Dempster \& Lerner, 1950 ; TAllis, 1962 ; Falconer, 1965 ; Thomson, 1972 ; CuRnow \& SMith, 1975).

It is assumed that the probability that an experimental unit responds in category $\mathbf{k}(\mathbf{k}=1, \ldots, \mathrm{c})$ is related to the values of $\mathbf{m}$ continuous underlying variables $\left(\ell_{1}, \ell_{2}, \ldots, \ell_{\mathrm{m}}\right)$ with thresholds $\left(\tau_{1}, \tau_{2}, \ldots, \tau_{\mathrm{m}}\right)$. The model for the underlying variables can be written as

$$
\begin{aligned}
\ell_{\mathrm{ijq}}=\eta_{\mathrm{ij}}+\mathrm{e}_{\mathrm{ijq}} \quad & \mathrm{i}=1,2, \ldots, \mathrm{m} \\
& \mathrm{j}=1,2, \ldots, \mathrm{s} \\
\mathrm{q} & =1,2, \ldots, \mathrm{n}_{\mathrm{j}+}
\end{aligned}
$$

Under polygenic inheritance, it may be assumed that the residuals $e_{i j q}$ have a multivariate normal distribution. We write :

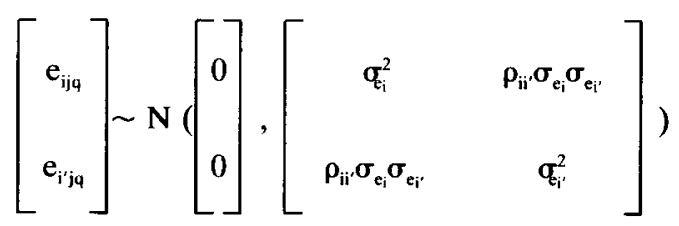

Given the location parameters $\eta_{\mathrm{ij}}$, the probability that an experimental unit of subclass $\mathrm{j}$ responses in category $\mathrm{k}$ is mapped via the thresholds by :

$$
\begin{aligned}
& P_{i},\left[r_{1}^{(k)} r_{2}^{(k)} \ldots r_{i}^{(k)} \ldots r_{m}^{(k)}\right]=\operatorname{Prob}\left\{\left[(-1)^{r_{i}^{(k)}} \ell_{1 j \varphi}<(-1)^{r_{1}^{(k)}} \tau_{1}\right] \Omega \ldots\left[(-1)^{r_{i}^{(k)}} \ell_{i j q}<(-1)^{r_{i}^{(k)}} \tau_{i}\right] \Omega\right. \\
& \left.\ldots\left[(-1)^{r_{m}^{(k)}} \ell_{m j q}<(-1)^{r_{m}^{(k)}} \tau_{m}\right] \mid \eta_{1 j}, \ldots, \eta_{i j}, \ldots \eta_{m j}\right\}
\end{aligned}
$$

with $r_{i}^{(k)}=(0,1)$. Because of the multivariate normality assumption, one may write for a given category, e.g., $[000 \ldots 0]$ :

$$
P_{j,(0 k) \ldots y)}=\int_{-\infty}^{\tau_{1}} \ldots \int_{-\infty}^{\tau_{i}} \ldots \int_{-\infty}^{\tau_{m}} \phi\left(x_{1}, \ldots, x_{i}, \ldots, x_{m} ; E\right) d x_{1} \ldots d x_{i} \ldots d x_{m}
$$

where $\phi\left(x_{1}, \ldots, x_{i}, \ldots, x_{m} ; E\right)$ is a multivariate normal density function with means $\eta_{\mathrm{ij}}(\mathrm{i}=1, \ldots, \mathrm{m} ; \mathrm{j}=1, \ldots, \mathrm{s})$, and variance-covariance matrix $\mathbf{E}$ as in (4).

Letting $y_{i}=\left(x_{i}-\eta_{i j}\right) / \sigma_{e j},(6)$ becomes :

$$
P_{j,|(00) \ldots 0|}=\int_{-\infty}^{\mu_{1 j}} \ldots \int_{-\infty}^{\mu_{i j}} \ldots \int_{-\infty}^{\mu_{m j}} \phi\left(y_{1}, \ldots, y_{i}, \ldots, y_{m} ; \mathbf{R}\right) d y_{1} \ldots d y_{i} \ldots d y_{m}
$$


where $\mu_{i j}=\left(\tau_{i}-\eta_{i j}\right) / \sigma_{e_{i}}$ and $\mathbf{R}$ is a matrix of residual correlations. In general, the probability of response in any category $\left[\mathbf{r}_{1}^{(\mathbf{k})} \ldots \mathbf{r}_{i}^{(k)} \ldots \mathbf{r}_{m}^{(k)}\right]$ is :

$P_{j},\left[r_{1}^{(k)} \ldots r_{i}^{(k)} \ldots r_{m}^{(k)}\right]=\int_{-\infty}^{\mu_{i j}^{(k)}} \ldots \int_{-\infty}^{\mu_{i j}^{(k)}} \ldots \int_{-\infty}^{\mu_{m i}^{(k)}} \phi\left(y_{1}^{(k)}, \ldots, y_{i}^{(k)}, \ldots, y_{m}^{(k)} ; \mathbf{R}^{(k)}\right) d y_{1}^{(k)} \ldots d y_{i}^{(k)} \ldots d y_{m}^{(k)}$

where $y_{i}^{(k)}=(-1)^{r_{i}^{(k)}} y_{i} ; \mu_{i j}^{(k)}=(-1)^{r_{i}^{(k)}} \mu_{i j}$, and $\mathbf{R}^{(k)}$ is a matrix with typical element :

$$
\rho_{\mathrm{ii}}^{(\mathbf{k})}=(-1)^{\left(\mathbf{r}_{\mathrm{i}}^{(\mathbf{k})}-r_{\mathrm{i}^{\prime}}^{(k)}\right.} \rho_{\mathrm{ii}}
$$

The next step is to model the $\mu_{\mathrm{ij}}$ 's, i.e., the distance between the threshold for the $\mathrm{i}^{\text {th }}$ underlying variate and the mean of the $\mathrm{j}^{\text {th }}$ subpopulation in units of residual standard deviation. Because of the assumption of multivariate normality, it is sensible to employ a linear model. Let :

$$
\boldsymbol{\mu}_{\mathrm{i}}=\mathbf{X}_{\mathrm{i}} \boldsymbol{\beta}_{\mathrm{i}}+\mathbf{Z}_{\mathrm{i}} \mathbf{u}_{\mathrm{i}} ; \mathbf{i}=1, \ldots, \mathbf{m}
$$

where $\boldsymbol{\mu}_{i}$ is an $s \times 1$ vector, $\mathbf{X}_{i}\left(Z_{i}\right)$ is a known incidence matrix of order $s \times p_{i}(s \times q)$, $\boldsymbol{\beta}_{i}$ is a vector of " fixed " effects and $\mathbf{u}_{\mathrm{i}}$ is a vector of " random " effects. In animal breeding, the $\beta$ 's are usually effects of environmental factors such as herd-year-seasons or age at calving, or of sub-populations (group of sires), which affect the data. The u's can be breeding values, transmitting abilities or producing abilities.

More generally :

$$
\boldsymbol{\mu}=\mathbf{X} \boldsymbol{\beta}+\mathbf{Z u}
$$

where : $\boldsymbol{\mu}^{\prime}=\left[\boldsymbol{\mu}_{1}^{\prime}, \ldots, \boldsymbol{\mu}_{m}^{\prime}\right]$

$$
\begin{aligned}
& \mathbf{X}=\bigoplus_{i=1}^{\mathbf{m}} \mathbf{X}_{\mathbf{i}} \\
& \boldsymbol{\beta}^{\prime}=\left[\boldsymbol{\beta}_{1}^{\prime}, \ldots, \boldsymbol{\beta}_{\mathrm{m}}^{\prime}\right] \\
& \mathbf{Z}=\bigoplus_{\mathbf{i}=1}^{\mathbf{m}} \mathbf{Z}_{\mathbf{i}} \\
& \mathbf{u}^{\prime}=\left[\mathbf{u}_{1}^{\prime}, \ldots, \mathbf{u}_{\mathrm{m}}^{\prime}\right]
\end{aligned}
$$

and $\oplus$ is the direct-sum operator.

\section{Statistical inference}

Inferences are based on Bayes theorem :

$$
\mathbf{f}(\boldsymbol{\theta} \mid \mathbf{Y}) \propto \mathrm{g}(\mathbf{Y} \mid \boldsymbol{\theta}) \cdot \mathbf{h}(\boldsymbol{\theta})
$$

where $\boldsymbol{\theta}^{\prime}=\left[\boldsymbol{\beta}^{\prime}, \mathbf{u}^{\prime}\right]$ is a vector of parameters and

$$
\begin{aligned}
& \mathbf{f}(\boldsymbol{\theta} \mid \mathbf{Y}) \text { : posterior density, } \\
& \mathbf{g}(\mathbf{Y} \mid \boldsymbol{\theta}): \text { likelihood function, }
\end{aligned}
$$

and

$$
\text { h (ө) : prior density. }
$$

It is assumed that all required variances and covariances are known at least to proportionality. 
The prior density is taken as multivariate normal so :

$$
\left[\begin{array}{l}
\boldsymbol{\beta} \\
\mathbf{u}
\end{array}\right] \sim \mathrm{N}\left(\left[\begin{array}{l}
\boldsymbol{\alpha} \\
\mathbf{0}
\end{array}\right],\left[\begin{array}{cc}
\boldsymbol{\Gamma} & \mathbf{0} \\
\mathbf{0} & \mathbf{G}
\end{array}\right]\right)
$$

where $\boldsymbol{\alpha}^{\prime}=\left[\boldsymbol{\alpha}_{1}{ }^{\prime}, \ldots, \boldsymbol{\alpha}_{\mathrm{i}}{ }^{\prime}, \ldots, \boldsymbol{\alpha}_{\mathrm{m}}\right] ; \boldsymbol{\alpha}_{\mathrm{i}}=\mathrm{E}\left(\boldsymbol{\beta}_{\mathrm{i}}\right)$;

$$
\Gamma=\left[\begin{array}{ccccc}
\Gamma_{11} & \ldots & \Gamma_{1 i} & \ldots & \Gamma_{\mathrm{lm}} \\
\boldsymbol{\Gamma}_{\mathrm{il}} & \ldots & \boldsymbol{\Gamma}_{\mathrm{ii}} & \ldots & \Gamma_{\mathrm{im}} \\
\boldsymbol{\Gamma}_{\mathrm{ml}} & \ldots & \boldsymbol{\Gamma}_{\mathrm{mi}} & \ldots & \boldsymbol{\Gamma}_{\mathrm{mm}}
\end{array}\right]
$$

where $\boldsymbol{\Gamma}_{\mathrm{ii}^{\prime}}=\operatorname{Cov}\left(\boldsymbol{\beta}_{\mathrm{i}}, \boldsymbol{\beta}_{\mathrm{i}}\right)$, and :

$$
\mathbf{G}=\left[\begin{array}{cccccc} 
& & & & \\
\mathbf{G}_{11} & \ldots & \mathbf{G}_{\mathrm{li}} & \ldots & \mathbf{G}_{\mathrm{lm}} \\
\mathbf{G}_{\mathrm{il}} & \ldots & \mathbf{G}_{\mathrm{ii}} & \ldots & \mathbf{G}_{\mathrm{im}} \\
\mathbf{G}_{\mathrm{ml}} & \ldots & \mathbf{G}_{\mathrm{mi}} & \ldots & \mathbf{G}_{\mathrm{mm}}
\end{array}\right]
$$

with $\mathbf{G}_{i i^{\prime}}=\operatorname{Cov}\left(\mathbf{u}_{\mathrm{i}}, \mathbf{u}_{\mathrm{i}^{\prime}}\right)$.

When the u's are breeding values or transmitting abilities, we can write :

$$
\mathbf{G}_{\mathrm{ii}^{\prime}}=\mathbf{A} \sigma_{\mathrm{ui}^{\prime}}
$$

with $\sigma_{u_{i i^{\prime}}}=\sigma_{u_{i}}^{2}$ when $i=i^{\prime}$. Above, $A$ is the matrix of additive genetic relationships between the $q$ individuals we wish to evaluate, and $\sigma_{\mathrm{u}}^{2}$ and $\sigma_{\mathrm{u}_{\mathrm{i}}}$ are the additive genetic variance for trait $i$, and the additive genetic covariance between traits $i$ and $i^{\prime}$, respectively.

More generally :

$$
\mathbf{G}=\mathbf{\Sigma}_{\mathbf{G}} \otimes \mathbf{A}
$$

is an $\mathrm{mq} \times \mathrm{mq}$ matric where $\Sigma_{\mathrm{G}}$ is the $\mathrm{m} \times \mathrm{m}$ additive genetic variance-covariance matrix.

The prior density is proportional to :

$h(\boldsymbol{\theta}) \propto \exp .\left\{-\frac{1}{2}\left[(\boldsymbol{\beta}-\boldsymbol{\alpha})^{\prime} \boldsymbol{\Gamma}^{-1}(\boldsymbol{\beta}-\boldsymbol{\alpha})+\mathbf{u}^{\prime} \mathbf{G}^{-1} \mathbf{u}\right]\right\}$

Given $\boldsymbol{\theta}$, the data in $\mathbf{Y}$ are conditionally independent following a multinominal distribution. The likelihood function is :

$$
g(\mathbf{Y} \mid \boldsymbol{\theta})=\prod_{j=1}^{s} \frac{n_{j+} !}{\prod_{k} n_{j . k} !} \prod_{k} P_{j . k . k}^{n_{j . k}}
$$


Because the posterior mean $\mathrm{E}(\boldsymbol{\theta} \mid \mathbf{Y})$ is technically difficult to evaluate, the posterior mode is taken as a Bayes point estimator. The mode minimizes expected loss when the loss function is :

$$
\sum_{\ell} \mathbf{d}_{\ell} ; \mathbf{d}_{\ell}=\left\{\begin{array}{l}
1 \text { if }\left|\theta_{\ell}-\hat{\theta}_{\ell}\right|>\epsilon \\
0 \quad \text { otherwise }
\end{array}\right.
$$

Above, $\epsilon$ is an arbitrarily small number (Box \& Tiao, 1973).

\section{Computation of the mode of the posterior distribution}

\section{General considerations}

From (11), (14) and (15), the log-posterior density can be written as :

$$
L(\theta)=\sum_{j=1}^{s} \sum_{k=1}^{2^{m}} n_{j . k} \log P_{j . k}-\frac{1}{2}\left[(\boldsymbol{\beta}-\boldsymbol{\alpha})^{\prime} \Gamma^{-1}(\boldsymbol{\beta}-\boldsymbol{\alpha})+\mathbf{u}^{\prime} \mathbf{G}^{-1} \mathbf{u}\right]+\text { const. }
$$

Suppose, a priori, that all vectors $\boldsymbol{\beta}$ are equally likely, i.e., prior knowledge about $\boldsymbol{\beta}$ is vague. This is equivalent to letting $\boldsymbol{\Gamma}^{-1} \rightarrow \mathbf{0}$, in which case (16) reduces to :

$\mathbf{L}(\boldsymbol{\theta})=\sum_{\mathrm{j}} \sum_{\mathbf{k}} \mathbf{n}_{\mathrm{j} . \mathrm{k}} \log \mathrm{P}_{\mathrm{j} . \mathrm{k}}-\frac{1}{2} \mathbf{u}^{\prime} \mathbf{G}^{-1} \mathbf{u}+$ const.

In order to get the mode of the posterior density, the derivatives of (17) with respect to $\boldsymbol{\theta}$ are equated to zero. However, the equations are not explicit in $\boldsymbol{\theta}$. The resulting non-linear system can be solved iteratively using the Newton-Raphson algorithm. This consists of iterating with :

$$
-\left[\frac{\partial^{2} \mathrm{~L}(\boldsymbol{\theta})}{\partial \boldsymbol{\theta} \partial \boldsymbol{\theta}^{\prime}}\right] \quad \boldsymbol{\Delta}^{(t)}=\left[\frac{\partial \mathrm{L}(\boldsymbol{\theta})}{\partial \boldsymbol{\theta}}\right]
$$

where $\Delta^{[t]}=\hat{\boldsymbol{\theta}}^{[t]}-\ddot{\boldsymbol{\theta}}^{[t-1]}$, and $\hat{\boldsymbol{\theta}}^{[t]}$ is a solution at the $\mathrm{t}^{\text {th }}$ iterate. Iterations were stopped when $\left[\Delta^{\prime} \Delta /\left(\Sigma_{i} p_{i}+m q\right)\right]^{0.5}$ was smaller than an arbitrarily small number.

\section{First derivatives}

The first derivatives of the log-posterior in (17) with respect to $\boldsymbol{\beta}_{\mathrm{i}}$ can be written as :

$$
\begin{aligned}
\frac{\partial L(\boldsymbol{\theta})}{\partial \boldsymbol{\beta}_{i}} & =\sum_{j=1}^{s} \sum_{k=1}^{2^{m}} n_{j . k} \frac{\partial \log P_{j . k}}{\partial \boldsymbol{\beta}_{i}} \\
& =\sum_{j=1}^{s} \mathbf{v}_{i j} \mathbf{x}_{i j}=\mathbf{X}_{i}^{\prime} \mathbf{v}_{i}
\end{aligned}
$$

where $x_{i j}$ is a $p_{i} \times 1$ vector containing the elements of the $j^{\text {th }}$ row of the $s \times p_{i}$ incidence matrix $\mathbf{X}_{i}$, and $v_{i}$ is an $s \times 1$ vector with elements $v_{i j}$ which have the form: 
$\mathbf{v}_{\mathrm{ij}}=\sum_{\mathbf{k}} \frac{\mathbf{n}_{\mathrm{j}, \mathrm{k}}}{\mathbf{P}_{\mathrm{j}, \mathrm{k}}} \frac{\partial \mathbf{P}_{\mathrm{j}, \mathrm{k}}}{\partial \mu_{\mathrm{ij}}}$

where $\mu_{i j}$ is the $j^{\text {th }}$ element in $\mu_{i}$ of (9).

If the subscript $\mathrm{j}$ is ignored, one can write :

$$
\begin{aligned}
& \frac{\partial \mathrm{P}_{\mathrm{k}}}{\partial \mu_{\mathrm{i}}}=(-1)^{\mathrm{r}^{(\mathrm{k})}} \phi\left(\mu_{\mathrm{i}}\right) \Phi_{\mathrm{m}-1}\left(\ldots \mathrm{h}_{\ell \mathrm{i}}^{(\mathrm{k})}, \ldots, \mathrm{h}_{\ell^{\prime} \mathrm{i}}^{(\mathrm{k})}, \ldots ; \ldots, \rho_{\ell \ell^{\prime}, \mathrm{i}}^{(\mathrm{k})}, \ldots\right) \\
& \left(\ell, \ell^{\prime}\right)=1, \ldots, \mathrm{m} ; \ell \neq \ell^{\prime} \neq \mathrm{i}
\end{aligned}
$$

where :

- $r_{i}^{(k)}=(0,1)$ is the $i^{\text {th }}$ bit in the index for category $k$.

- $\Phi_{m-1}($.$) is a normal integral with \mathrm{m}-1$ dimensions.

- $\mathrm{h}_{t \mathrm{i}}^{(\mathrm{k})}=(-1)^{\mathrm{r} \mathrm{r}^{(\mathrm{k})}} \mathrm{h}_{\ell \mathrm{i}}$

- $\mathrm{h}_{\ell \mathrm{i}}=\frac{\mu_{t}-\rho_{\mathrm{i}} \mu_{\mathrm{i}}}{\sqrt{\left(1-\rho_{t \mathrm{i}}^{2}\right)}}$

- $\rho_{t t^{\prime}, i}^{(k)}=(-1)^{r(k)}-r^{(k)} \rho_{\ell t^{\prime}, i}$

- $\rho_{t t^{\prime}, \mathrm{i}}=$ residual correlation between liability variates $\ell$ and $\ell^{\prime}$ when the variate $\mathrm{i}$ is fixed.

In order to illustrate $(20)$, let $\mathrm{m}=3$ and $\mathrm{c}=8$, i.e., 3 binary traits so that there are $2^{3}=8$ response categories. Application of (20) to the 3-bit-digit [101] yields :

$$
\frac{\partial \mathbf{P}_{[101]}}{\partial \mu_{3}}=-\phi\left(\mu_{3}\right) \Phi_{2}\left(-h_{13}, h_{23} ;-\rho_{12.3}\right)
$$

Similarly, suppose $\mathrm{m}=4$ and $\mathrm{c}=2^{4}=16$. Application of (20) to the 4-bit-digit [0110] gives :

$$
\frac{\partial \mathrm{P}_{[0110]}}{\partial \mu_{3}}=-\phi\left(\mu_{3}\right) \Phi_{3}\left(h_{13},-h_{23} ; h_{43} ;-\rho_{12.3},-\rho_{24.3}, \rho_{14.3}\right)
$$

It should be mentioned that the expression in (20) is consistent with notation employed by JoHnson \& KoTz (1972) for bivariate and trivariate normal integrals.

The first derivatives of the log-posterior with respect to $\mathbf{u}_{i}$ are :

$$
\frac{\partial L(\theta)}{\partial \dot{u}_{i}}=Z_{i}^{\prime} \mathbf{v}_{i}-\sum_{i^{\prime}=1}^{m} G^{i^{\prime} \mathbf{u}_{i^{\prime}}}
$$

where $\mathbf{G}^{i^{\prime}}$ is the block corresponding to traits $i$ and $i^{\prime}$ in the inverse of $\mathbf{G}$ defined in (13).

\section{Second derivatives}

First, consider :

$$
\begin{gathered}
\frac{\partial^{2} \mathrm{~L}(\boldsymbol{\theta})}{\partial \boldsymbol{\beta}_{\mathrm{i}} \partial \boldsymbol{\beta}_{\mathrm{i}^{\prime}}{ }^{\prime}}=-\sum_{\mathrm{j}} \mathbf{w}_{\mathrm{i}^{\prime}{ }^{\prime} \mathrm{j}} \mathbf{x}_{\mathrm{ij}} \mathbf{x}_{\mathrm{i}^{\prime} \mathrm{j}}^{\prime} \\
=-\mathbf{X}_{\mathrm{i}}^{\prime} \mathbf{W}_{\mathrm{i}^{\prime}} \mathbf{X}_{\mathrm{i}^{\prime}}
\end{gathered}
$$


where $\mathbf{W}_{\mathrm{i}}$, is an $\mathbf{s} \times \mathbf{s}$ diagonal matrix with elements :

$$
w_{i i^{\prime}, j}=-\frac{\partial v_{i j}}{\partial \mu_{i i^{\prime} j}}=-\sum_{k} n_{j, k} \frac{\partial^{2} \log P_{j, k}}{\partial \mu_{i j} \partial \mu_{i^{\prime} j}}
$$

The form of the second derivative in the preceding expression is described in the appendix. Similarly :

$$
\frac{\partial^{2} \mathbf{L}(\boldsymbol{\theta})}{\partial \mathbf{u}_{\mathrm{i}} \partial \mathbf{u}_{\mathrm{i}^{\prime}}{ }^{\prime}}=-\mathbf{Z}_{\mathrm{i}}^{\prime} \mathbf{W}_{\mathrm{ii}^{\prime}} \mathbf{Z}_{\mathrm{i}^{\prime}}-\mathbf{G}^{\mathrm{i}^{\prime}}
$$

and :

$\frac{\partial^{2} \mathrm{~L}(\boldsymbol{\theta})}{\partial \boldsymbol{\beta}_{\mathrm{i}} \partial \mathbf{u}_{\mathrm{i}^{\prime}}^{\prime}}=-\mathbf{X}_{\mathrm{i}}^{\prime} \mathbf{W}_{\mathrm{i}{ }^{\prime}} \mathbf{Z}_{\mathrm{i}^{\prime}}$

\section{Equations}

First, we observe that (18) can be written as :

$$
\begin{aligned}
{\left[\frac{-\partial^{2} L(\boldsymbol{\theta})}{\partial \boldsymbol{\theta} \partial \boldsymbol{\theta}^{\prime}}\right]_{\boldsymbol{\theta}=\hat{\boldsymbol{\theta}}^{(t-1)}} \hat{\boldsymbol{\theta}}^{(t)} } & =\left[\frac{-\partial^{2} \mathbf{L}(\boldsymbol{\theta})}{\partial \boldsymbol{\theta} \partial \boldsymbol{\theta}^{\prime}}\right]_{\boldsymbol{\theta}=\hat{\boldsymbol{\theta}}^{[t-1]}} \hat{\boldsymbol{\theta}}^{[t-1]} \\
& +\left[\frac{\partial L(\boldsymbol{\theta})}{\partial \boldsymbol{\theta}}\right]_{\boldsymbol{\theta}=\hat{\boldsymbol{\theta}}^{[t-1]}}
\end{aligned}
$$

Collecting the first and second derivatives in (19) through (24), the system of equations requiring solution can be written as :

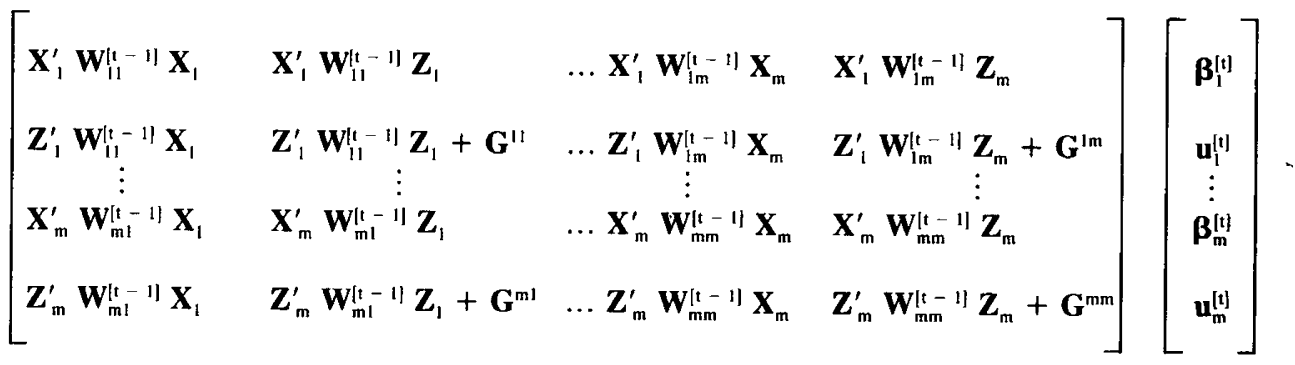




$$
=\left[\begin{array}{l}
\mathbf{X}_{1}^{\prime} \mathbf{W}_{11}^{[t-1]} \mathbf{y}_{1}^{[t-1]}+\sum_{i \neq 1} \mathbf{X}_{1}^{\prime} \mathbf{W}_{1 i}^{[t-1]} \mathbf{y}_{i}^{[t-1]} \\
\mathbf{Z}_{1}^{\prime} \mathbf{W}_{11}^{[t-1]} \mathbf{y}_{1}^{[t-1]}+\sum_{i \neq 1} \mathbf{Z}_{1}^{\prime} \mathbf{W}_{\mathrm{li}}^{[t-1]} \mathbf{y}_{i}^{[t-1]} \\
\mathbf{X}_{m}^{\prime} \mathbf{W}_{m m}^{[t-1]} \mathbf{y}_{m}^{[t-1]}+\sum_{i \neq m} \mathbf{X}_{m}^{\prime} \mathbf{W}_{m i}^{[t-1]} \mathbf{y}_{i}^{[t-1]} \\
\mathbf{Z}_{m}^{\prime} \mathbf{W}_{m m}^{[t-1]} \mathbf{y}_{m}^{[t-1]}+\sum_{i \neq m} \mathbf{Z}_{m}^{\prime} \mathbf{W}_{m i}^{[t-1]} \mathbf{y}_{i}^{[t-1]}
\end{array}\right]
$$

where :

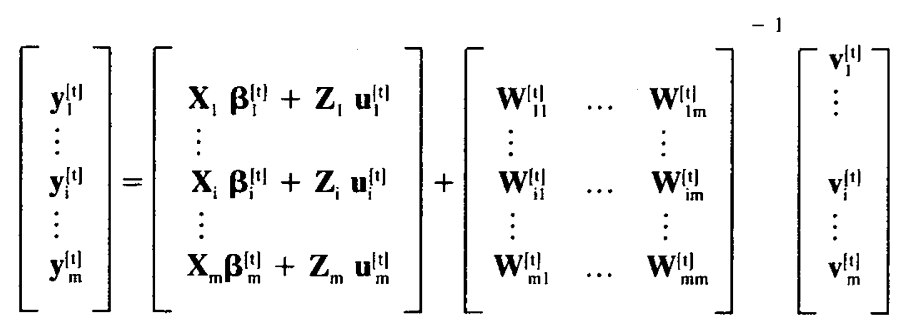

are "working variates". Note that the system in (25) has a remarkable parallel with the equations arising in multiple-trait evaluation via mixed linear models (HENDERSON \& QuAAs, 1976). Also, observe that the inverse matrix required in (26) is easy to obtain because the $\mathbf{W}_{\mathrm{ii}}$, submatrices are diagonal.

\section{Numerical application to three binary traits}

\section{A. Data}

Data on 3 binary traits - calving preparation, calving difficulty and calf viability - were obtained from 48 Blonde d'Aquitaine heifers mated to the same bull and assembled to calve in the Casteljaloux Station, France. Each record on an individual included information about region of origin, season of calving, sex of calf, sire of heifer, calving preparation ( "bad » or " good»), calving difficulty score (1: normal birth, 2: slight assistance, $3:$ assisted, $4:$ mechanical aid, $5:$ caesarean) and calf viability (dead, "poor" or "good" viability). For the purpose of the analysis "bad" calving preparation was coded as 0 , "good" preparation as 1 ; calving difficulty scores 1-3 were recoded as 0 and 4-5 as 1 ; dead or "poor» viable calves were coded as 0 and calves having "good" viability were coded as 1 . The data were arranged in an $30 \times 2^{3}$ contingency array presented in table 1 .

Raw frequencies in the 8 categories of response and summed over traits for each level of the factors considered are shown in table 2 . Overall, only 25 p. 100 of the heifers had a "good " calving preparation, 75 p. 100 of the calvings were normal or slightly assisted, and 79 p. 100 of the calves had " good " viability. Differences between sires suggest a variation for all traits which could be used for selection. The data suggest an association between "good " preparation and " easy " calving, "good " preparation and viability and especially between « easy" calving and " good" viability. 
TABLE 1

Distribution of records by region of origin, season of calving, sex of calf and sire of heifer subclasses.

\begin{tabular}{|c|c|c|c|c|c|c|c|c|c|c|c|c|}
\hline \multirow{2}{*}{$\begin{array}{l}\text { Sub- } \\
\text { class }\end{array}$} & \multirow[b]{2}{*}{ Region } & \multirow[b]{2}{*}{ Season } & \multirow{2}{*}{$\begin{array}{c}\text { Sex } \\
\text { of } \\
\text { calf * }\end{array}$} & \multirow{2}{*}{$\begin{array}{c}\text { Sire } \\
\text { of } \\
\text { heifer }\end{array}$} & \multicolumn{8}{|c|}{ Counts in category } \\
\hline & & & & & $\begin{array}{l}(000) \\
=1\end{array}$ & $\begin{array}{l}(001) \\
=2\end{array}$ & $\begin{array}{l}(010) \\
=3\end{array}$ & $\begin{array}{l}(011) \\
=4\end{array}$ & $\begin{array}{l}(100) \\
=5\end{array}$ & $\begin{array}{l}(101) \\
=6\end{array}$ & $\begin{array}{c}(110) \\
=7\end{array}$ & $\begin{array}{c}(111) \\
=8\end{array}$ \\
\hline 1 & 1 & 1 & 1 & 1 & 0 & 1 & 0 & 0 & 0 & 1 & 0 & 0 \\
\hline 2 & 1 & 1 & 2 & 1 & 0 & 1 & 0 & 0 & 0 & 0 & 0 & 0 \\
\hline 3 & 1 & 2 & 2 & 1 & 1 & 3 & 0 & 0 & 0 & 0 & 0 & 0 \\
\hline 4 & 2 & 2 & 2 & 1 & 0 & 1 & 0 & 0 & 0 & 0 & 0 & 0 \\
\hline 5 & 2 & 1 & 2 & 1 & 0 & 1 & 0 & 0 & 0 & 1 & 0 & 0 \\
\hline 6 & 1 & 1 & 1 & 2 & 0 & 1 & 1 & 0 & 0 & 0 & 0 & 0 \\
\hline 7 & 1 & 1 & 2 & 2 & 0 & 1 & 0 & 0 & 0 & 0 & 0 & 0 \\
\hline 8 & 1 & 2 & 1 & 2 & 0 & 1 & 0 & 0 & 0 & 0 & 1 & 0 \\
\hline 9 & 1 & 2 & 2 & 2 & 0 & 0 & 1 & 0 & 0 & 0 & 0 & 0 \\
\hline 10 & 2 & 2 & 1 & 2 & 0 & 2 & 0 & 0 & 0 & 0 & 0 & 0 \\
\hline 11 & 1 & 1 & 1 & 3 & 0 & 0 & 0 & 0 & 0 & 1 & 0 & 0 \\
\hline 12 & 2 & 1 & 1 & 3 & 0 & 0 & 0 & 0 & 0 & 1 & 0 & 0 \\
\hline 13 & 2 & 1 & 2 & 3 & 0 & 1 & 0 & 0 & 0 & 0 & 0 & 0 \\
\hline 14 & 2 & 2 & 1 & 3 & 1 & 0 & 0 & 0 & 0 & 0 & 0 & 0 \\
\hline 15 & 2 & 2 & 2 & 3 & 1 & 1 & 0 & 0 & 0 & 0 & 0 & 0 \\
\hline 16 & 1 & 2 & 1 & 4 & 0 & 0 & 0 & 1 & 0 & 0 & 0 & 0 \\
\hline 17 & 1 & 2 & 2 & 4 & 0 & 1 & 1 & 0 & 0 & 0 & 0 & 0 \\
\hline 18 & 2 & 1 & 1 & 4 & 0 & 1 & 0 & 0 & 0 & 0 & 0 & 0 \\
\hline 19 & 1 & 1 & 1 & 5 & 1 & 0 & 0 & 0 & 0 & 0 & 0 & 0 \\
\hline 20 & 1 & 1 & 2 & 5 & 0 & 0 & 0 & 0 & 0 & 1 & 0 & 0 \\
\hline 21 & 1 & 2 & 1 & 5 & 0 & 2 & 0 & 0 & 0 & 1 & 0 & 1 \\
\hline 22 & 1 & 2 & 2 & 5 & 1 & 0 & 0 & 0 & 0 & 0 & 0 & 0 \\
\hline 23 & 2 & 1 & 1 & 5 & 0 & 0 & 0 & 1 & 0 & 0 & 0 & 0 \\
\hline 24 & 2 & 1 & 2 & 5 & 0 & 1 & 0 & 0 & 0 & 0 & 0 & 0 \\
\hline 25 & 2 & 2 & 1 & 5 & 0 & 0 & 0 & 1 & 0 & 0 & 0 & 1 \\
\hline 26 & 1 & 1 & 1 & 6 & 0 & 0 & 0 & 1 & 0 & 0 & 0 & 0 \\
\hline 27 & 1 & 1 & 2 & 6 & 0 & 0 & 0 & 1 & 0 & 1 & 0 & 0 \\
\hline 28 & 1 & 2 & 1 & 6 & 0 & 1 & 1 & 0 & 0 & 1 & 0 & 0 \\
\hline 29 & 1 & 2 & 2 & 6 & 0 & 1 & 0 & 0 & 0 & 0 & 0 & 0 \\
\hline 30 & 2 & 1 & 2 & 6 & 0 & 1 & 0 & 0 & 0 & 1 & 0 & 0 \\
\hline
\end{tabular}

* I: malc, 2 : femalc.

\section{B. Model}

The same model was used to describe the 3 underlying variables for calving preparation, calving difficulty and calf viability. The model for the distance between the threshold and the mean of subpopulations $j$ for the $i^{\text {th }}$ underlying variate was :

$$
\begin{aligned}
\mu_{i j}=r_{i k}+t_{i l}+g_{i m}+s_{i n} ; & i=1,2,3 \\
j & =1, \ldots, 30
\end{aligned}
$$




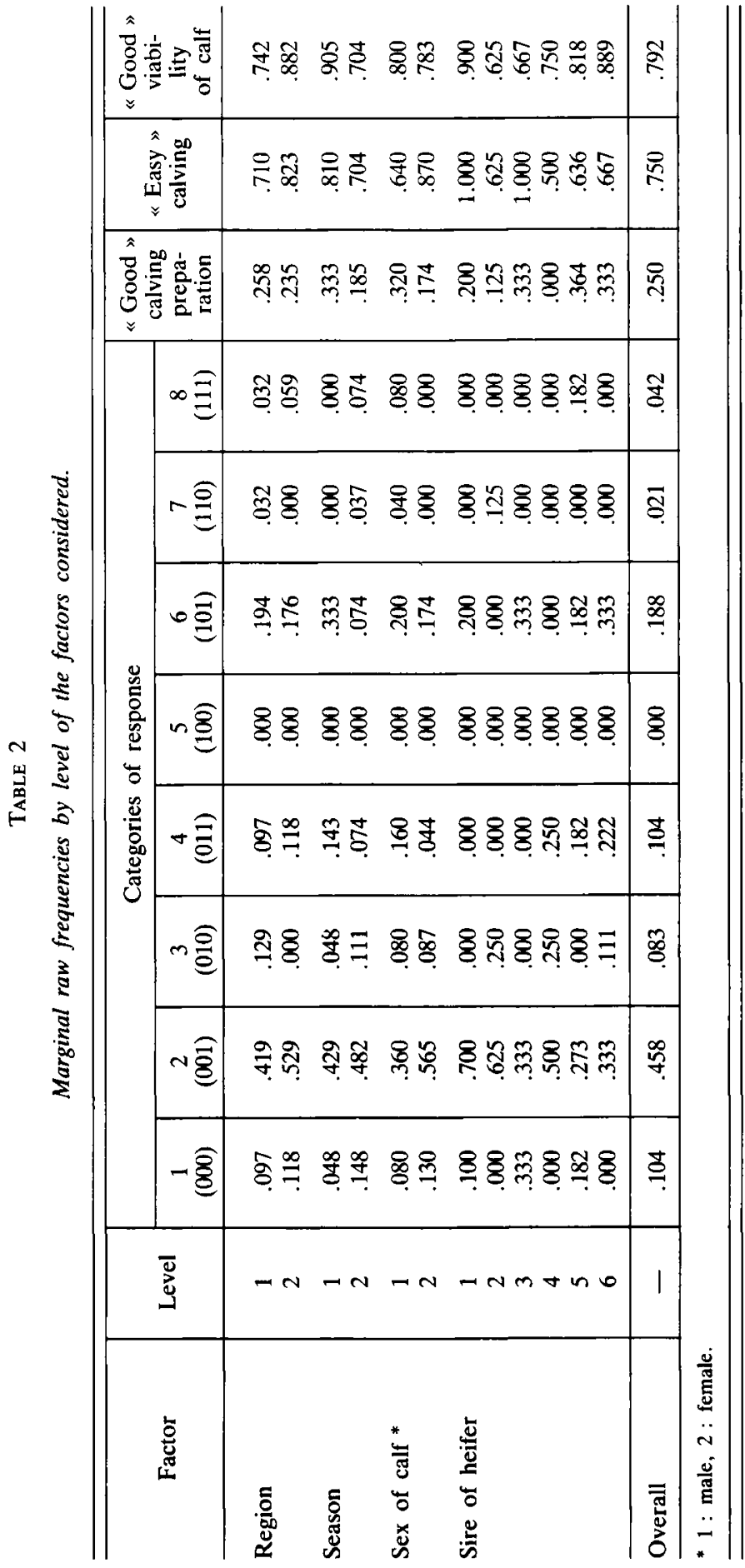


where $\mathbf{r}_{i k}$ is the effect of the k'th region of origin $(k=1,2), t_{i 1}$ is the effect of the l'th season of calving $(l=1,2), \mathrm{g}_{\mathrm{im}}$ is the effect of the $\mathrm{m}$ 'th sex of calf $(\mathrm{m}=$ male, female) and $s_{\text {in }}$ is the effect of the $n$ 'th sire of heifer.

In order to reparameterize the models to full rank, the $\boldsymbol{\beta}_{i}$-vectors were taken as :

$$
\boldsymbol{\beta}_{i}=\left[\begin{array}{l}
r_{i 1}+t_{i 2}+g_{i 2} \\
r_{i 2}+t_{i 2}+g_{i 2} \\
t_{i 1}-t_{i 2} \\
g_{i 1}-g_{i 2}
\end{array}\right] ; i=1,2,3
$$

The first two elements of $\boldsymbol{\beta}_{\mathrm{i}}$ correspond to the distance between threshold and subpopulation mean for female calves born in season 2 out of heifers coming from regions 1 and 2 , respectively. The third and fourth elements represent the difference between calving seasons and between male and female calves, respectively.

\section{Prior information}

Dispersion parameters used to implement the multiple trait sire evaluation are shown below :

\begin{tabular}{l|c|c|c} 
& $\begin{array}{c}\text { Calving } \\
\text { preparation (1) }\end{array}$ & $\begin{array}{c}\text { Calving } \\
\text { difficulty (2) }\end{array}$ & $\begin{array}{c}\text { Calf } \\
\text { viability (3) }\end{array}$ \\
\cline { 2 - 4 } & .27 & -.64 & .47 \\
$(2)$ & -.40 & .23 & -.50 \\
$3)$ & .25 & -.35 & .20 \\
\hline
\end{tabular}

The diagonal elements are heritabilities of the 3 traits in the underlying scale ; the elements above and below the diagonal represent genetic and residual correlations, respectively. These values were taken from GogUE (1975, unpublished Charolais data) after an approximate transformation to the conceptual scale. Prior knowledge about $\boldsymbol{\beta}$ was assumed to be vague, so the $\log$ prior density function is :

$$
\operatorname{lnf}(\mathbf{u})=-\frac{1}{2} \mathbf{u}^{\prime} \mathbf{G}^{-1} \mathbf{u}+\text { const. }
$$

where :

$$
\mathbf{G}=\Sigma \mathbf{u} \otimes \mathbf{A} ; \mathbf{\Sigma} \mathbf{u}=\left[\begin{array}{ccc}
1 / \lambda_{1} & -.64 /\left(\lambda_{1} \lambda_{2}\right)^{0.5} & .47 /\left(\lambda_{1} \lambda_{3}\right)^{0.5} \\
1 / \lambda_{2} & -.50 /\left(\lambda_{2} \lambda_{3}\right)^{0.5} \\
& 1 / \lambda_{3}
\end{array}\right]
$$

$\otimes$ is the Kronecker product and $\lambda_{i}=\left(4-h_{i}^{2}\right) / h_{i}^{2}$. 


\section{Iteration}

Iteration was carried out with equations (18). The starting values were obtained by applying in (18) :

$$
\begin{aligned}
& \mathbf{W}_{\mathrm{i}}=\operatorname{Diag}\left(\mathrm{n}_{\mathrm{j}+}\right) ; \mathrm{i}=1,2,3 \\
& \mathrm{j}=1, \ldots, 30 \\
& \mathbf{W}_{\mathrm{ii}}=\mathbf{0} \quad ; \mathrm{i} \neq \mathrm{i}^{\prime} \\
& \mathrm{i}, \mathrm{i}^{\prime}=1,2,3 \\
& \boldsymbol{\beta}_{\mathrm{i}}=\mathbf{0}, \mathbf{u}_{\mathrm{i}}=\mathbf{0} \quad ; \mathrm{i}=1,2,3 \\
& v_{i}=\left\{v_{i j}\right\} \text { with } v_{i j}=\sum_{k} n_{j, k} \text { for } k \text { such as } r_{i}^{(k)}=0 \\
& \mathrm{i}=1,2,3 \\
& \mathrm{j}=1, \ldots, 30
\end{aligned}
$$

and :

$$
\mathbf{G}^{-1}=\operatorname{Diag}\left(\lambda_{\mathrm{i}}\right) \otimes \mathbf{A}^{-1} ; \mathrm{i}=1,2,3
$$

Using the above values, Newton-Raphson yields as a first iterate solutions to univariate linear « mixed model » equations applied to $(0,1)$ data. The criterion to stop iteration was :

$$
\left[\boldsymbol{\Delta}^{\prime} \mathbf{\Delta} / 3(\mathrm{p}+\mathrm{q})\right]^{0.5}<10^{-6},
$$

where $\boldsymbol{\Delta}$ is the vector of corrections in (18), $\mathrm{p}$ is the order of $\boldsymbol{\beta}_{\mathrm{i}}$ and $\mathrm{q}$ is the order of $u_{i}$. The required bivariate and trivariate normal integrals were calculated using formulae described by Ducroce (1984) based on the method of DuTt \& Soms (1976).

\section{E. Results}

The Newton-Raphson-algorithm required 6 iterations to satisfy the above convergence criterion. From previous investigations it is known that the number of iterates is nearly independent of the initial values for $\boldsymbol{\beta}$ and $\mathbf{u}$ used to start iteration. For sire ranking purposes iteration could have stopped after the $3^{\text {rd }}$ or $4^{\text {th }}$ round as it can be seen in table 3 .

For interpretation of the results it must be taken into account that the higher the value of $\mu_{i j}$ or of elements contributing to $\mu_{i j}$, the higher is the probability of response in categories coded as 0 . This implies that low values of $\mu_{1}$ (calving preparation) and $\mu_{3}$ (calf viability) are desirable while high values of $\mu_{2}$ (calving ease) are desirable. For example, cows having male calves had a better calving preparation, male calves had a higher viability but caused more calving difficulty than female calves.

Sires can be ranked using the estimated effects in the conceptual scale presented in tables 3 and 4 , or by using estimated response probabilities as pointed out in Gianola \& Foulley (1983 a, 1983 b), Foulley et al. (1983) and in Foulley \& Gianola (1984). Marginal probabilities estimated for the 6 sires using the trivariate evaluation, raw 
TABLE 3

Solutions to the trivariate model by round of iteration.

\begin{tabular}{|c|c|c|c|c|}
\hline \multirow{2}{*}{ Trait } & \multirow{2}{*}{ Parameter } & \multicolumn{3}{|c|}{ Iteration ${ }^{(1)}$} \\
\hline & & III & IV & VI \\
\hline $\begin{array}{l}\text { Calving } \\
\text { preparation }\end{array}$ & $\begin{array}{l}r_{11}+t_{12}+g_{12} \\
r_{12}+t_{12}+g_{12} \\
t_{11}-t_{12} \\
g_{11}-g_{12} \\
s_{11} \\
s_{12} \\
s_{13} \\
s_{14} \\
s_{15} \\
s_{16}\end{array}$ & $\begin{array}{r}1.2864 \\
1.3419 \\
-0.5375 \\
-0.6329 \\
-0.0698 \\
0.1286 \\
-0.0487 \\
0.1242 \\
-0.0759 \\
-0.0585\end{array}$ & $\begin{array}{r}1.2892 \\
1.3452 \\
-0.5386 \\
-0.6351 \\
-0.0701 \\
0.1290 \\
-0.0479 \\
0.1239 \\
-0.0760 \\
-0.0590\end{array}$ & $\begin{array}{r}1.2892 \\
1.3452 \\
-0.5386 \\
-0.6351 \\
-0.0701 \\
0.1291 \\
-0.0479 \\
0.1239 \\
-0.0760 \\
-0.0590\end{array}$ \\
\hline $\begin{array}{l}\text { Calving } \\
\text { difficulty }\end{array}$ & $\begin{array}{l}\mathrm{r}_{21}+\mathrm{t}_{22}+\mathrm{g}_{22} \\
\mathrm{r}_{22}+\mathrm{t}_{22}+\mathrm{g}_{22} \\
\mathrm{t}_{21}-\mathrm{t}_{22} \\
\mathrm{~g}_{21}-\mathrm{g}_{22} \\
\mathrm{~s}_{21} \\
\mathrm{~s}_{22} \\
\mathrm{~s}_{23} \\
\mathrm{~s}_{24} \\
\mathrm{~s}_{25} \\
\mathrm{~s}_{26}\end{array}$ & $\begin{array}{r}0.8851 \\
1.2115 \\
0.3673 \\
-0.7643 \\
0.1458 \\
-0.0892 \\
0.0767 \\
-0.1080 \\
-0.0148 \\
-0.0104\end{array}$ & $\begin{array}{r}0.8853 \\
1.2134 \\
0.3695 \\
-0.7655 \\
0.1461 \\
-0.0896 \\
0.0760 \\
-0.1078 \\
-0.0148 \\
-0.0099\end{array}$ & $\begin{array}{r}0.8853 \\
1.2134 \\
0.3696 \\
-0.7656 \\
0.1461 \\
-0.0896 \\
0.0760 \\
-0.1078 \\
-0.0148 \\
-0.0099\end{array}$ \\
\hline $\begin{array}{l}\text { Calf } \\
\text { viability }\end{array}$ & $\begin{array}{l}r_{31}+t_{32}+g_{32} \\
r_{32}+t_{32}+g_{32} \\
t_{31}-t_{32} \\
g_{31}-g_{32} \\
s_{31} \\
s_{32} \\
s_{33} \\
s_{34} \\
s_{35} \\
s_{36}\end{array}$ & $\begin{array}{r}-0.3387 \\
-0.8067 \\
-0.7239 \\
-0.1015 \\
-0.1099 \\
0.1085 \\
0.0513 \\
0.0342 \\
-0.0194 \\
-0.0647\end{array}$ & $\begin{array}{r}-0.3366 \\
-0.8447 \\
-0.7727 \\
-0.0877 \\
-0.1110 \\
0.1098 \\
0.0534 \\
0.0332 \\
-0.0194 \\
-0.0660\end{array}$ & $\begin{array}{r}-0.3365 \\
-0.8460 \\
-0.7743 \\
-0.0871 \\
-0.1110 \\
0.1098 \\
0.0535 \\
0.0332 \\
-0.0194 \\
-0.0661\end{array}$ \\
\hline
\end{tabular}

(1) Iteration I corresponds to univariate linear mixed model solutions on $(0,1)$ scores.

frequencies and marginal probabilities estimated from univariate analyses are presented in table 5. Trivariate probabilities for each sire were estimated as :

$$
\hat{\Pi}_{\mathrm{nc}}=\sum_{\mathrm{klm}} \sum \mathrm{a}_{\mathrm{klm}} \Phi\left[(-1)^{\mathrm{r}_{1}^{(\mathrm{c})}} \mu_{1 \mathrm{j}},(-1)^{\mathrm{r}_{2}^{(\mathrm{c})}} \mu_{2 j},(-1)^{\mathrm{r}_{3}^{(\mathrm{c})}} \mu_{3 \mathrm{j}} ; \mathbf{R}^{(\mathrm{c})}\right]
$$

where $\mathrm{n}$ is sire $(\mathrm{n}=1, \ldots, 6), \mathrm{c}$ is a given category, $\mathrm{a}_{\mathrm{klm}}$ is a weight such that $\sum \sum \sum \mathrm{a}_{\mathrm{klm}}=1$ and $\mu_{\mathrm{ij}}=\mathrm{r}_{\mathrm{ik}}+\mathrm{t}_{\mathrm{il}}+\mathrm{g}_{\mathrm{im}}+\mathrm{s}_{\mathrm{in}}$; a was taken as $1 / 8$ for all combinations of $(\mathrm{k}, \mathrm{l}, \mathrm{m})$ because there were 8 region $\times$ season $\times$ sex of calf subclasses per sire. For reasons described above the sires with the highest response probability in the desirable 
TABLE 4

Estimates of the parameters and their posterior precision for univariate and trivariate models.

\begin{tabular}{|c|c|c|c|}
\hline \multirow{2}{*}{ Trait } & \multirow{2}{*}{ Parameter } & \multicolumn{2}{|c|}{ Model } \\
\hline & & Univariate & Trivariate \\
\hline $\begin{array}{l}\text { Calving } \\
\text { preparation }\end{array}$ & $\begin{array}{l}r_{11}+t_{12}+g_{12} \\
r_{12}+t_{12}+g_{12} \\
t_{11}-t_{12} \\
g_{11}-g_{12} \\
s_{11} \\
s_{12} \\
s_{13} \\
s_{14} \\
s_{15} \\
s_{16}\end{array}$ & $\begin{array}{r}1.2620 \pm .4667 \\
1.3698 \pm .5187 \\
-0.5776 \pm .4222 \\
-0.5697 \pm .4361 \\
-0.0141 \pm .2436 \\
0.1091 \pm .2445 \\
-0.0445 \pm .2506 \\
0.0961 \pm .2565 \\
-0.1018 \pm .2359 \\
-0.0729 \pm .2397\end{array}$ & $\begin{array}{r}1.2892 \pm .4678 \\
1.3452 \pm .5105 \\
-0.5386 \pm .4190 \\
-0.6351 \pm .4375 \\
-0.0701 \pm .2392 \\
0.1291 \pm .2397 \\
-0.0479 \pm .2481 \\
0.1239 \pm .2532 \\
-0.0760 \pm .2318 \\
-0.0590 \pm .2370\end{array}$ \\
\hline $\begin{array}{l}\text { Calving } \\
\text { difficulty }\end{array}$ & $\begin{array}{l}r_{21}+t_{22}+g_{22} \\
r_{22}+t_{22}+g_{22} \\
t_{21}-t_{22} \\
g_{21}-g_{22} \\
s_{21} \\
s_{22} \\
s_{23} \\
s_{24} \\
s_{25} \\
s_{26}\end{array}$ & $\begin{array}{r}0.8986 \pm .4131 \\
1.2423 \pm .5359 \\
0.2617 \pm .4281 \\
-0.7215 \pm .4383 \\
0.1559 \pm .2302 \\
-0.0473 \pm .2244 \\
0.1057 \pm .2353 \\
-0.0886 \pm .2334 \\
-0.0565 \pm .2218 \\
-0.0692 \pm .2252\end{array}$ & $\begin{array}{r}0.8853 \pm .4103 \\
1.2134 \pm .5230 \\
0.3696 \pm .4302 \\
-0.7656 \pm .4414 \\
0.1461 \pm .2245 \\
-0.0896 \pm .2203 \\
0.0760 \pm .2308 \\
-0.1078 \pm .2308 \\
-0.0148 \pm .2162 \\
-0.0099 \pm .2216\end{array}$ \\
\hline $\begin{array}{l}\text { Calf } \\
\text { viability }\end{array}$ & $\begin{array}{l}\mathrm{r}_{31}+\mathrm{t}_{32}+\mathrm{g}_{32} \\
\mathrm{r}_{32}+\mathrm{t}_{32}+\mathrm{g}_{32} \\
\mathrm{t}_{31}-\mathrm{t}_{32} \\
\mathrm{~g}_{31}-\mathrm{g}_{32} \\
\mathrm{~s}_{31} \\
\mathrm{~s}_{32} \\
\mathrm{~s}_{33} \\
\mathrm{~s}_{34} \\
\mathrm{~s}_{35} \\
\mathrm{~s}_{36}\end{array}$ & $\begin{array}{r}-0.3158 \pm .3849 \\
-0.8810 \pm .5116 \\
-0.7508 \pm .4695 \\
-0.1151 \pm .4404 \\
-0.0904 \pm .2148 \\
0.0930 \pm .2126 \\
0.1010 \pm .2200 \\
-0.0112 \pm .2200 \\
-0.0225 \pm .2109 \\
-0.0698 \pm .2141\end{array}$ & $\begin{array}{r}-0.3365 \pm .3871 \\
-0.8460 \pm .5076 \\
-0.7743 \pm .4717 \\
-0.0871 \pm .4418 \\
-0.1110 \pm .2118 \\
0.1098 \pm .2099 \\
0.0535 \pm .2175 \\
0.0332 \pm .2177 \\
-0.0194 \pm .2067 \\
-0.0661 \pm .2107\end{array}$ \\
\hline
\end{tabular}

categories (table 5) were sires 5 and 1 for calving preparation and calf viability, respectively - the sires with the smallest values in the conceptual scale - and sire 1 for calving difficulty - the sire with the highest value in the conceptual scale.

Sire rankings for all 3 traits were similar but not the same in univariate and trivariate evaluations as is can be seen in tables 4 and 5. The discrepancy between rankings based on raw frequencies and those obtained using proposed procedure is due to the fact that the unequal distribution of sires among region $\times$ season $\times$ sex of calf subclasses is not taken into account when raw frequencies are used. The approximate standard errors in table 4 indicate a very slight increase in accuracy in the trivariate analysis. 
TABLE 5

Marginal probabilities of response by sire estimated by raw data, univariate and trivariate models.

\begin{tabular}{l|c|c|c|c}
\hline \multirow{2}{*}{ Estimation by } & Sire & \multicolumn{3}{|c}{ Trait } \\
\cline { 3 - 5 } & & $\begin{array}{c}\text { "Good » calving } \\
\text { preparation }\end{array}$ & $\begin{array}{c}\text { « Easy » } \\
\text { calving }\end{array}$ & $\begin{array}{c}\text { « Good » } \\
\text { viability }\end{array}$ \\
\hline \multirow{2}{*}{ Raw data } & 1 & .2000 & 1.0000 & .9000 \\
& 2 & .1250 & .6250 & .6250 \\
& 3 & .3333 & 1.0000 & .6667 \\
& 4 & .0000 & .5000 & .7500 \\
Univariate & 5 & .3636 & .6364 & .8182 \\
Model & 6 & .3333 & .6667 & .8889 \\
& 1 & .2425 & .8202 & .8439 \\
& 2 & .2159 & .7670 & .8009 \\
& 3 & .2597 & .8078 & .7989 \\
Trivariate & 4 & .2194 & .7552 & .8262 \\
Model & 5 & .2772 & .7644 & .8288 \\
& 6 & .2683 & .7608 & .8394 \\
& 1 & .2717 & .8172 & .8471 \\
& 2 & .2144 & .7551 & .7950 \\
& 3 & .2650 & .7998 & .8092 \\
& 4 & .2158 & .7498 & .8141 \\
& 5 & .2735 & .7759 & .8266 \\
& 6 & .2683 & .7772 & .8372 \\
\hline
\end{tabular}

\section{Discussion}

This paper presents a further extension of the methodology developed by Gianola \& Foulley $(1982,1983 a, 1983 b)$ and Harville \& MEe (1984) aimed to predict merit of animals assuming a multifactorial genetic model and categorical phenotypic values. An alternative approach has been presented by GlLmour (1983).

The threshold model provides a conceptual basis to dichotomize (in $\mathrm{m}$ dimensions) a multivariate normal distribution. Non-linearity arises when the distribution is rendered discrete, and a multidimensional normal integral provides the link between values in the normal scale and the realizations in the discrete (observed scale). Nevertheless, there is a linear component in the model : the argument of the integral consists of $\mathrm{m}$ variates which follow an m-dimensional linear model. Hence, the approach can be regarded as belonging to the class of generalized linear models (McCullagh \& Nelder, 1983). The Bayesian treatment of " random » effects provides an additional level of generalization, and the procedure described in this paper can be viewed as belonging to a class of "generalized mixed linear models " of which the multiple trait mixed linear model is only an individual member. These relationships become explicit in the system of equations used for iteration. 
The non-linearity arising in the problem has important implications which merit discussion. First, it is possible to evaluate candidates for selection, e.g., sires, directly in the probability scale. As pointed out by Gianola \& Foulley (1983a, 1983b) and Foulley et al. (1983), the selection criterion would involve a weighted linear function of probabilities. For example, the probability that the progeny of a particular sire has a certain combination of attributes could be averaged out over factors such as age at calving or herd-year-seasons. The weights for the " elementary " probabilities can be chosen arbitrarily so they may differ, depending on the formulation of the problem, from the weights suggested by the relative frequencies appearing in the data set analyzed. In traits such as prolificacy, viability and calving ease, comparisons among sires depend greatly on « environmental » conditions such as age at calving, so there is a need for averaging out probabilities with respect to certain levels of « fixed » effects. In the numerical example presented, elementary probabilities were estimated for the sake of simplicity by evaluating integrals with $\mu_{\mathrm{ij}}$ parameters replaced by posterior modes. Because modes are not known to be functionally invariant, the estimates so obtained may not always be satisfactory. In addition, this procedure does not take into account uncertainty associated with the estimates of $\mu_{\mathrm{ij}}$. The approach followed by Harville \& MeE (1984) might be more appropriate although tedious to compute. Computationally, the problem could be tackled by deriving a point estimator obtained from the posterior distribution of elementary probabilities.

Second, iteration with (25) has important numerical consequences. In principle, $\mathrm{s} \times 2^{\mathrm{m}}$ multidimensional normal integrals need to be evaluated at each iterate. This implies that computing time and precision may become limiting factors. Fortunately, reasonably efficient algorithms exist for computation of low $(\mathrm{m}<6$, DuTT \& Soms, $1976)$ or high $(6 \leq \mathrm{m} \leq 20$, DEAK, 1980) multivariate normal integrals. The method of DuTT \& Soms (1976) has been described and applied to animal breeding situations by Ducroce (1984). An additional problem is the number of equations requiring solution, and the number of iterations until convergence. The order of the computations is comparable to that arising in multiple trait evaluations via mixed linear model, times the number of iterates. Hence, considerable research in the area of numerical analysis is warranted to make the proposed multidimensional evaluation procedure feasible in the large scale data sets usually employed in, e.g., progeny testing programs.

In the example considered, the non-linear system of equations was solved using Newton-Raphson and this required 6 iterates and 306 seconds of CPU. We also used Fisher's scoring procedure with :

$$
w_{i i^{\prime}, j}=n_{j+} \sum_{k} \frac{1}{P_{j k}} \cdot \frac{\partial P_{j k}}{\partial \mu_{i}} \cdot \frac{\partial P_{j k}}{\partial \mu_{i^{\prime}}}
$$

and this algorithm satisfied the convergence criterion after 10 iterates and 545 seconds. This illustrates that scoring, although algebraically appealing, may have undesirable effects on the cost of the evaluations obtained.

A multivariate evaluation requires knowledge of genetic and residual correlations among traits. In this paper, as in the case of multiple trait evaluation by mixed linear models, the required covariance matrices have been assumed to be known. Univariate versus multivariate analyses have been discussed in the context of continuous data by, among others, Pollak et al. (1984), Schaeffer (1984) and Thompson \& Meyer (1985). Reduction of prediction error variance due to use of correlated information depends on the form of the genetic and residual variances and covariances. The most gain is achieved when genetic and residual correlations are large and opposite in sign and 
when progeny group sizes are small. This theoretical advantage may dissipate when correlations are either small or estimated imprecisely. Hence, multivariate analyses do not necessarily lead to more precise predictors. On the other hand, a multivariate approach can help to correct biases from selection on correlated traits if the analysis includes the records used for selection decisions. This is also true beyond the multivariate normal distribution (Fernando \& Gianola, 1986 ; Gianola \& Fernando, 1986). Because selection (especially sequential) results in missing information, it would be useful to extend the methodology developed in this paper to accommodate this case. This has been done by Foulley \& Gianola (1986) and this will be reported elsewhere.

Received September 4, 1985.

Accepted March 10, 1986.

\section{References}

Berger P.J., Freeman A.E., 1978. Prediction of sire merit for calving difficulty. J. Dairy Sci., 61, 1146-1156.

Box G.E.P., Tiao G.C., 1973. Bayesian Inference in Statistical Analysis. 519 pp., AddisonWesley, Reading, Mass.

Curnow R.N., Smith C., 1975. Multifactorial models for familial diseases in man. J. Roy. Statist. Soc., Ser. A, 138, 131-156.

DEAK I., 1980. Three digit accurate multiple normal probabilities. Numer. Math., 35, 369-380.

DempSter E.R., Lerner I.M., 1950. Heritability of threshold characters. Genetics, 35, 212-235.

Ducroce V, 1984. Conséquences sur le progrès génétique laitier d'une sélection sur des caractères secondaires chez les bovins. Génét. Sél. Evol., 16, 467-490.

Dutr J.E., Soms A.P., 1976. An integral representation technique for calculating general multivariate probabilities with an application to multivariate $\chi^{2}$. Commun. Stat. Theor. Method, A5, 3777-3788.

FALCONER D.S., 1965. The inheritance of liability to certain diseases estimated from the incidence among relatives. Ann. Hum. Genet., 29, 51-76.

Fernando R.L., Gianola D., 1986. Optimal properties of the conditional mean as a selection criterion. Theor. Appl. Genet., in press.

Foulley J.L., Gianola D., Thompson R., 1983. Prediction of genetic merit from data on categorical and quantitative variates with an application to calving difficulty, birth weight and pelvic opening. Génét. Sél. Evol., 15, 407-424.

Foulley J.L., Gianola D., 1984. Estimation of genetic merit from bivariate "all or none » responses. Génét. Sél. Evol., 16, 285-306.

Foulley J.L., Gianola D., 1986. Sire evaluation for multiple binary responses when information is missing on some traits. J. Dairy Sci. (accepted).

Gianola D., 1980a. A method of sire evaluation for dichotomies. J. Anim. Sci., 51, 1266-1271.

Gianola D., 1980b. Genetic evaluation of animals for traits with categorical responses. J. Anim. Sci., 51, 1272-1276.

Gianola D., Fernando R.L., 1986. Bayesian methods in animal breeding theory. J. Anim. Sci. in press.

Gianola D., Foulley J.L., 1982. Non-linear prediction of latent genetic liability with binary expression: An empirical Bayes approach. Proceedings of the $2^{\text {nd }}$ World Congress of Genetics Applied to Livestock Production, Madrid, Oct. 4-8, 1972, 7, 293-303, Editorial Garsi, Madrid. 
Gianola D., Foulley J.L., 1983a. New techniques of prediction of breeding value for discontinuous traits. 32 ${ }^{\text {nd }}$ Annual National Breeders Roundtable, May 6, 1983, Saint-Louis, Missouri.

Gianola D., Foulley J.L., 1983b. Sire evaluation for ordered categorical data with a threshold model. Génét. Sél. Evol., 15, 201-223.

Gilmour A.R., 1983. The estimation of genetic parameters for categorical traits, 195 pp., Unpublished PhD Thesis, Massey University, New Zealand.

Harville D.A., Mee R.W., 1984. A mixed-model procedure for analyzing ordered categorical data. Biometrics, 40, 393-408.

Henderson C.R., 1973. Sire evaluation and genetic trends. Proceeding of the Animal Breeding and Genetics Symposium in honor of Dr. Jay L. Lush, Blacksburg, Virginia, July 29, 1972, 10-41. ASAS-ADSA, Champaign, Illinois.

Henderson C.R., QuaAs R.L., 1976. Multiple trait evaluation using relatives'records. J. Anim. Sci., 43, 1188-1197.

Johnson L.N., Kotz S., 1972. Distributions in statistics. Continuous multivariate distributions. 333 pp., John Wiley \& Sons, Inc., New York.

McCullagh P., Nelder J.A., 1983. Generalized linear models. 263 pp., Chapman \& Hall, London.

Pollak E.J., v.d. Werk J., QuaAs R.L., 1984. Selection bias and multiple trait evaluation. J. Dairy Sci., 67, 1590-1595.

QuAaS R.L., VAN VLECK L.D., 1980. Categorical trait sire evaluation by best linear unbiased prediction of future progeny frequencies. Biometrics, 36, 117-122.

Robertson A., LERner I.M., 1949. The heritability of all-or-none traits : viability of poultry. Genetics, 34, 395.

SCHAEFFER L.R., 1984. Sire and cow evaluation under multiple trait models. J. Dairy Sci., 67, 1567-1580.

Schaeffer L.R., Wilton J.W., 1976. Methods of sire evaluation for calving ease. J. Dairy Sci., 59, 544-551.

TALLIS G.M., 1962. The maximum likelihood estimation of correlation from contingency tables. Biometrics, 18, 342-353.

Thompson R., 1972. The maximum likelihood approach to the estimate of liability. Ann. Hum. Genet., 36, 221-231.

Thompson R., Meyer K., 1985. Theoretical aspects in the estimation of breeding values for multitrait selection. $36^{\text {th }}$ Annual Meeting of the European Association for Animal Production, Sept. 30.-Oct. 3., Kallithea-Kassandra-Khalkidhiki, Thessaloniki, Greece, 20 pp.

Wright S., 1983. An analysis of variability in number of digits in an inbred strain of guinea pigs. Genetics, 19, 506-536.

\section{Appendix}

\section{Derivation of second derivatives}

Ignoring subscripts $\mathrm{j}$ and $\mathrm{k}$, and using logarithmic derivatives, we can write :

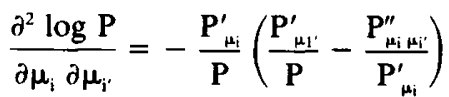

Because $\mathrm{P}_{\mu}^{\prime}$ is given in $(20)$, only $\mathrm{P}_{\mu \mu^{\prime}}^{\prime \prime} / \mathrm{P}_{\mu}^{\prime}$ needs to be computed for all $\left(i, i^{\prime}\right)=1, \ldots, m$. In view of $(20)$ : 
a) $P_{\mu_{i}}^{\prime \prime} / P_{\mu_{i}}^{\prime}=-\mu_{i}+\frac{\partial \Phi_{m-1}(.)}{\partial \mu_{i}} \cdot \frac{1}{\Phi_{m-1}(.)}$

where $\Phi_{\mathrm{m}-1}($.$) is an \mathrm{m}-1$ multivariate normal integral with argument as in (20).

Now :

$\frac{\partial \Phi_{m-1}(.)}{\partial \mu_{i}}=\sum_{\ell \neq i} \frac{\partial \Phi_{m-1}(.)}{\partial h_{\ell i}^{(k)}} \cdot \frac{\partial h_{\ell i}^{(k)}}{\partial \mu_{i}}$

$\frac{\partial h_{i i}^{(k)}}{\partial \mu_{i}}=(-1)^{r_{i}^{(k)}+1} \rho_{t i}\left(1-\rho_{t i}^{2}\right)^{-\frac{1}{2}}$

$\frac{\partial \Phi_{m-1}(.)}{\partial h_{t i}^{(k)}}=\Phi\left(h_{t i}\right) \Phi_{m-2}\left(\ldots h_{m . t i}^{(k)}, \ldots h_{n . t i}^{(k)}, \ldots ; \ldots \rho_{m . k i}^{(k)} \ldots\right)$

$$
(\mathrm{m}, \mathrm{n})=1, \ldots, \mathrm{m}, \text { and } \mathrm{m} \neq \mathrm{n} \neq \ell \neq \mathrm{i}
$$

Above, $\Phi_{m-2}($.$) is an m-2$ dimensional multivariate normal integral, and :

$h_{m . t i}^{(k)}=(-1)^{r_{m}^{(k)}} h_{m . t i}$

$h_{m . t i}=\frac{\mu_{m}-\beta_{m t . i} \mu_{t}-\beta_{m i . t} \mu_{i}}{\left(1-\rho_{m . t i}^{2}\right)^{\frac{1}{2}}}$

and :

$\beta_{\mathrm{m} t . \mathrm{i}}=\frac{\rho_{\mathrm{m} t}-\rho_{\mathrm{mi}} \rho_{\mathrm{i}}}{1-\rho_{t \mathrm{i}}^{2}}$

is the standard partial regression of $y_{m}$ on $y_{t}$; also $\rho_{\mathrm{m}, \ell_{\mathrm{i}}}^{2}$ is the squared multiple correlation coefficient obtained in the regression of $y_{m}$ on $y_{t}$ and $y_{i}$. Further,

$$
\rho_{m n . t i}^{(k)}=(-1)^{(k m)-r_{n}^{(k)}} \rho_{m n . t i}
$$

where $\rho_{m n . t i}$ is the partial correlation between $y_{m}$ and $y_{n}$ given $y_{\ell}$ and $y_{i}$. If $R$ is the residual correlation matrix between variates $(i, \ell, m)$ and $\mathbf{R}=T^{\prime} T$, then $T$ is the upper triangular matrix in the Cholesky decomposition, and $h_{m . t i}$ is the third element of the $1 \times 3$ vector $\left[\mu_{i}, \mu_{t}, \mu_{m}\right] \times \mathbf{T}_{3 \times 3}^{-1}$.

Inserting (A4) and (A5) in (A3) and using this in (A2), one obtains :

$$
\frac{\mathbf{P}^{\prime \prime} \mu_{i}}{\mathbf{P}^{\prime} \mu_{i}}=-\mu_{i}+\frac{\sum_{\ell \neq i}(-1)^{r^{(k)+1}} \rho_{\ell i}\left(1-p_{t i}^{2}\right)^{-\frac{1}{2}} \phi\left(h_{\ell i}\right) \Phi_{m-2}(.)}{\Phi_{m-1}(.)}
$$

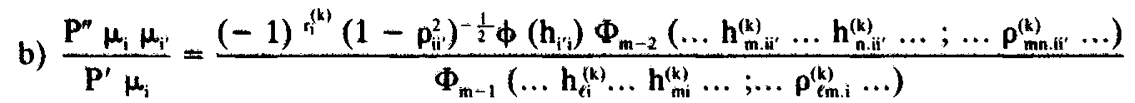

$\ell \neq i$ and $i^{\prime}$

$m \neq i$ and $i^{\prime}$

$n+i$ and $i^{\prime}$

$\ell \neq m \neq n$

c) Illustration for 3 traits $(m=3)$

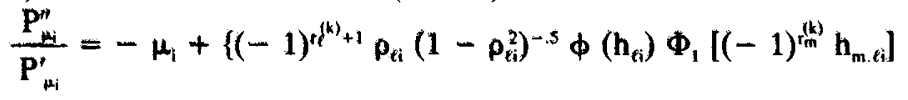




$$
\begin{aligned}
& \left.+(-1)^{r_{m}^{(k)}+1} \rho_{\mathrm{mi}}\left(1-\rho_{\mathrm{mi}}^{2}\right)^{-.5} \phi\left(\mathrm{h}_{\mathrm{mi}}\right) \Phi_{1}\left[(-1)^{r^{(k)}} h_{t . \mathrm{mi}}\right]\right\} / \\
& \Phi_{2}\left[(-1)^{r^{(k)}} h_{f i},(-1)^{r_{m i}^{(k)}} h_{m i} ;(-1)^{r^{(k)}-r_{m}^{(k)}} \rho_{c m .1}\right]
\end{aligned}
$$

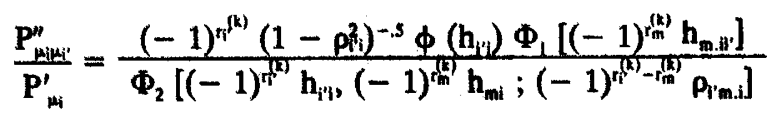

with $i, i^{\prime}$ being any permutation of $1,2,3$. 